\title{
Ultraviolet A radiation induces cortistatin overexpression and activation of somatostatin receptors in ARPE-19 cells
}

\author{
MARIA ELISABETTA CLEMENTI ${ }^{1}$, BEATRICE SAMPAOLESE ${ }^{1}$, \\ GIACOMO LAZZARINO ${ }^{2}$ and GIUSEPPE TRINGALI ${ }^{3}$
}

\author{
${ }^{1}$ CNR-ICRM Institute of Chemistry of Molecular Recognition (ICRM), Institute of Biochemistry and \\ Clinical Biochemistry; ${ }^{2}$ Institute of Biochemistry and Clinical Biochemistry; ${ }^{3}$ Institute of Pharmacology, \\ Catholic University School of Medicine, I-00168 Rome, Italy
}

Received September 15, 2017; Accepted January 16, 2018

DOI: $10.3892 / \mathrm{mmr} .2018 .8547$

\begin{abstract}
Long-term exposure to ultraviolet (UV) radiation is associated with pathological alterations of the retinal pigment epithelium (RPE). It has been indicated that Cortistatin (CST) and somatostatin (SST) are able to inhibit the neurodegeneration of the RPE associated with diabetic retinopathy and retinal ischemia via activation of SST receptors (SSTRs). To the best of our knowledge, the present study indicated for the first time that treatment with UV-A (30 and $60 \mathrm{~min}$ ) causes an increase of CST expression, rather than SST, which was linked with the upregulation of $\mathrm{STTR}_{3,4,5}$ subtype receptor gene expression levels. The study revealed that: i) SST and CST mRNA expression were both detected under basal conditions in a human retinal pigment epithelial cell line (Arpe-19); ii) SST expression remained constant from baseline to $1 \mathrm{~h}$ of UV-A treatment; iii) CST mRNA expression levels were 80 times increased compared with time 0 and after $30 \mathrm{~min}$ of exposition to ultraviolet irradiation; iv) $\mathrm{SSTR}_{1}, \mathrm{SSTR}_{2} \mathrm{mRNA}$ and low levels of $\mathrm{SSTR}_{4}$ were expressed in basal conditions, whereas SSTR3 and SSTR5 mRNA were not detected under the same conditions; and v) only $\mathrm{SSTR}_{3}, \mathrm{SSTR}_{4}$ and $\mathrm{SSTR}_{5}$ were overexpressed after UV-A treatment, although in a different way. In conclusion, the findings provide reasonable evidence to support the pathophysiological role of the CST/SST/SSTRs system in the adaptive response of the RPE exposed to UV-A radiation.
\end{abstract}

\section{Introduction}

Cortistatin (CST) is a endogenous neuropeptide cloned from human, rat and mouse tissues, which exhibits a remarkable

Correspondence to: Dr Giuseppe Tringali, Institute of Pharmacology, Catholic University School of Medicine, Largo F. Vito 1, I-00168 Rome, Italy

E-mail: giuseppe.tringali@unicatt.it

Key words: cortistatin, somatostatin, somatostatin receptors, retinal pigment epithelium, ultraviolet A radiation exposure, ARPE-19 cell line, neuropeptides structural and functional resemblance with somatostatin (SST) $(1,2)$. Both peptides share the ability to bind and activate all five cloned SST receptors $\left(\mathrm{SSTR}_{1-5}\right)$, with similar efficacy and potency (3). Despite these analogies, the profile of CST is not simply redundant but shows unique and even opposite actions from those exerted by SST, especially in immune and central nervous system (4-9). However, the mechanisms underlying these biological differences are still unknown.

It is currently known that CST and SST have a wide distribution in many organs $(10)$, including the retina $(11,12)$. However, if on one hand there are numerous experimental evidences on the expression, receptors and signalling mechanisms of SST that are involved in the physio-pathology of the retina (13), on the other hand there is a paucity of published data about CST and retina.

CST is expressed in human retina: more in the Retinal Pigment Epithelium (RPE) than in the neuroretina. Low levels of neuropeptide gene expression have been associated with apoptosis and glial activation, supporting the neuroprotective role of CST in diabetic retinopathy (12) and other retinal disorders (14). RPE cells, a monolayer of cells between the neuroretina and the choroid, play an important role in the maintenance of retina homeostasis. These cells can be exposed to various extracellular stimuli that promote their death and consequently to be the trigger of several eye diseases. Exposure to solar ultraviolet (UV) radiation is an external stressor, which may induce in these cells the production of reactive oxygen species (ROS), mitochondrial dysfunction, DNA damage, increase of apoptotic activity, leading to irreversible cellular necrosis (15-17).

To aid in our understanding on the pathophysiological role of CST in RPE, we investigated the modulation of neuropeptide gene expression. In fact, our finds display that: i) SST and CST mRNA expression are both detected in basal conditions in a human retinal pigment epithelial cell line (Arpe-19) after UV-A radiation exposure. Moreover we assessed the relationship among CST, SST and its receptor subtypes $\left(\mathrm{SSTR}_{1-5}\right)$ in the same experimental paradigm.

\section{Materials and methods}

Cell lines. Human RPE cells (ARPE-19 cell line, originally obtained from the American Type Cell Culture-CRL-2302-and 
kindly provided by Professor Stefano Cacchione, University of Rome 'La Sapienza') were used. The cell line was verified by the BMR Genomics S.r.l. Cell Line Authentication Service (Padova, Italy; ref. Nr 130264) using short tandem repeat analysis and an amelogenin gender-determining locus. Percent match between the submitted sample and the database profile was $100 \%$ (17). The cells were used between passages 5 and 8 and grown in 50/50 Ham's F12/Dulbecco's modified Eagle's Medium (Gibco; Thermo Fisher Scientific, Inc., Walthan, MA, Usa), supplemented with $15 \%$ (vol/vol) fetal bovine serum (Gibco; Thermo Fisher Scientific, Inc., Waltham, MA, Usa) and $100 \mathrm{U} / \mathrm{ml}$ penicillin/streptomycin in a humidified incubator at $37^{\circ} \mathrm{C}, 5 \% \mathrm{CO}_{2}$ and $95 \% \mathrm{O}_{2}$. The cells were plated into $6 \mathrm{~cm}$ of diameters cell culture dishes $\left(1 \times 10^{6}\right.$ cells) for the experiments. UV exposure was produced by UV lamp (Vilber Lourmat VL-62C Power 6W) in a custom designed UV irradiation unit at $37^{\circ} \mathrm{C}$ with $5 \% \mathrm{CO}_{2}$. The UV-A exposure of cells (at $365 \mathrm{~nm}$ ) were performed at $10 \mathrm{~cm}$ from the source for 30 or $60 \mathrm{~min}$, with an intensity of approximately $0.06 \mathrm{~J} / \mathrm{cm}^{2} / \mathrm{sec}$. Following UV-A treatment the cells were incubated for $24 \mathrm{~h}$ and successively used for different experimental procedures (17).

Cell viability. Cell viability was evaluated by MTS reduction assay, $24 \mathrm{~h}$ afterwards UV-treatments. The intracellular soluble 'formazan' produced by cellular reduction of the MTS was determined by recording the absorbance using an automatic microplate photometer at a wavelength of $490 \mathrm{~nm}$; cell viability was expressed as a percentage of surviving cell (18).

Reverse transcription-quantitative polymerase chain reaction $(R T-q P C R)$. Total RNA was isolated from the cells using PureLink ${ }^{\circledR}$ RNA Mini Kit and the elimination of any genomic DNA was performed by on-column DNAse treatment (Life technology; Thermo Fisher Scientific, Inc., Walthan, MA, USA). RNA concentration was evaluated by spectrophotometric reading at 280 and $260 \mathrm{~nm}$. Total RNA was used for first strand cDNA synthesis with SCRIPT cDNA Synthesis Kit and Oligo-dT, as random primer (Jena Bioscience GmbH, Jena, Germany). The PCR was performed with about $150 \mathrm{ng}$ cDNA using PCRBio Classic Taq (PCR Biosystems Ltd; London Bioscience Innovation Centre, London, NW1 ONH, United Kingdom). Experimental protocols for semiquantitative PCR reactions were: Denaturation, $95^{\circ} \mathrm{C}$ for $3 \mathrm{~min}$; followed by 40 cycles of denaturation at $95^{\circ} \mathrm{C}$ for $15 \mathrm{sec}$. Sequences of primers and temperature of annealing used for PCR analysis are reported in Table I. PCR products were then analysed by $1.5 \%$ agarose gels electrophoresis in TBE $1 \mathrm{X}$ Buffer. Image acquisition and product analysis was made by Bio-Rad imaging systems with Quantity One ${ }^{\circledR} 1-\mathrm{D}$ analysis software. The density of the PCR bands were divided by that of the housekeeping gene (GAPDH) and expressed as a percentage of the control band density.

Statistical analysis. Data were analysed by one-way ANOVA, followed by post-hoc Dunnett's test for comparing all treatment with control or by post hoc Newman-Keuls for comparisons between group means, when appropriate, using a PrismTM computer program (GraphPad, San Diego, CA, USA). All results was presented as the mean \pm SEM of at least three different experiments, unless otherwise specified. Differences were considered statistically significant if $\mathrm{P}<0.05$.

\section{Results}

ARPE-19 cell viability following exposure to ultraviolet $U V$-A irradiation. Preliminary experiments were carried out to investigate the modulation of CST and SST gene expression in ARPE-19 cells after $30 \mathrm{~min}$ and $1 \mathrm{~h}$ of UV-A exposure. The cells showed no signs of alteration nor cellular degeneration after UV radiation exposure compared to control group not exposed, as also demonstrated by experiments of cell vitality [Cell viability (\%) $\mathrm{n}=6$ : Control, 100; 30' radiation, 97.28 \pm 2.0 ; 60 ' radiation, $96.52 \pm 2.4]$. These data confirm what was previously seen from our group: treatment with UV-A radiation caused a reduction in cell viability from $2 \mathrm{~h}$ onwards as a result of apoptotic events that were manifested after 30-60 min of exposure (17).

SST and CST gene expression levels in ARPE-19 cells exposed to ultraviolet $U V$-A irradiation. SST and CST mRNA expression were both detected in basal conditions, although CST levels were significantly lower compared with those of SST. After 30 and 60 min of UV-A radiation exposure, the SST mRNA levels remained constant with a slight tendency to grow (but not in a significant manner) after an hour of treatment (Fig. 1). On the contrary the CST, slightly expressed in basal conditions, was significantly over-expressed already after 30 min of UV-A treatment. In fact, after half an hour, the CST mRNA levels were 80 times more higher, compared to time 0 , and they remained constant in subsequent $30 \mathrm{~min}$ (Fig. 1).

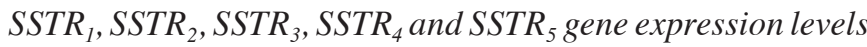
in ARPE-19 cells exposed to ultraviolet UV-A irradiation. A second series of experiments were performed in order to ascertain whether CST and SST gene expression variations, observed after UV-A exposure, were linked to a modulation of SST receptors $\left(\mathrm{SSTR}_{1-5}\right)$. PCR analysis showed the presence of $\mathrm{SSTR}_{1}, \mathrm{SSTR}_{2}$ mRNA and low but detectable levels of SSTR in basal condition. On the contrary $\mathrm{SSTR}_{3}$ and $\mathrm{SSTR}_{5}$ mRNA were not detected under same conditions (Figs. 2 and 3).

The $\mathrm{SSTR}_{1}$ and $\mathrm{SSTR}_{2}$ mRNA levels did not differ after 30 or 60 min UV-A radiation exposure (Fig. 2). In contrast $\mathrm{SSTR}_{3}, \mathrm{SSTR}_{4}$ and $\mathrm{SSTR}_{5}$ were over-expressed already after 30 min of UV-A treatment (Fig. 3). SSTR3 was most over-expressed with mRNA levels that were 6 times higher after only $30 \mathrm{~min}$ of treatment compared to control not irradiated (Fig. 3a). SSTR 4 expression doubled after $30 \mathrm{~min}$ of UV-A radiations and remained constant until the end of the experiment (Fig. 3b). Finally, SSTR $_{5}$ was overexpressed in a time-dependent manner; indeed the SSTR5 mRNA levels doubled approximately at each experimental time point (Fig. 3c).

\section{Discussion}

The findings of the present study show for the first time that one-hour of continuous exposition to UV-A radiations causes in ARPE-19 cells an increase of CST mRNA levels, rather than 
Table I. Primer sequences used for the PCR studies.

\begin{tabular}{|c|c|c|c|c|}
\hline Gene & Primers & $\mathrm{Ta}\left({ }^{\circ} \mathrm{C}\right)$ & Product size $(b p)$ & Cycles \\
\hline \multirow[t]{2}{*}{ GAPDH } & F 5'-AACGGATTTGGTCGTATTG-3' & 58 & 208 & 40 \\
\hline & R 5'-GGAAGATGGTGATGGGATT-3' & & & \\
\hline \multirow[t]{2}{*}{ SST } & F 5'-GGCTGCGCTGTCCATCGTC-3' & 59 & 285 & 40 \\
\hline & R 5'-CAGCCAGCTTTGCGTTCTCG-3' & & & \\
\hline \multirow[t]{2}{*}{ CST } & F 5'-CTCCAGTCAGCCCACAAGAT-3' & 63 & 173 & 40 \\
\hline & R 5'-CAAGCGAGGAAAGTCAGGAG-3' & & & \\
\hline \multirow[t]{2}{*}{$\mathrm{SSTR}_{1}$} & F 5'-CGCTGGCTGGTGGGCTTCGTGTTG-3' & 62 & 481 & 40 \\
\hline & R 5'-GCCGCCGGACTCCAGGTTCTCAG-3' & & & \\
\hline \multirow[t]{2}{*}{$\mathrm{SSTR}_{2}$} & F 5'-ACAGCTGTGCCAACCCTATC-3' & 55 & 358 & 40 \\
\hline & R 5'-AGCTGACTCAAACACCGTTCT-3' & & & \\
\hline \multirow[t]{2}{*}{$\mathrm{SSTR}_{3}$} & F 5'-GCGAGCCGGCTTCATCATCTACAC-3' & 65 & 517 & 40 \\
\hline & R 5'-GACCCGGCCGTTCATCTCCTTC-3' & & & \\
\hline \multirow[t]{2}{*}{$\mathrm{SSTR}_{4}$} & F 5'-TGGTCGGCAGTCTTCGTGGTCTAC-3' & 62 & 516 & 40 \\
\hline & R 5'-CTTGCGGCCGGGTTCTGGT-3' & & & \\
\hline \multirow[t]{2}{*}{$\mathrm{SSTR}_{5}$} & F 5'-GCGGCCTGGGTCCTGTCTCT-3' & 65 & 627 & 40 \\
\hline & R 5'-CCCCCGCCTGCACTCTCAC-3' & & & \\
\hline
\end{tabular}

GAPDH, glyceraldehyde 3-phosphate dehydrogenase; SST, somatostatin; CST, cortistatin; SSTR $_{1}$, somatostatin receptor 1; SSTR 2 , Somatostatin Receptor 2; $\mathrm{SSTR}_{3}$, Somatostatin Receptor 3; $\mathrm{SSTR}_{4}$, somatostatin receptor 4; $\mathrm{SSTR}_{5}$, somatostatin receptor 5; Ta, annealing temperature; $\mathrm{F}$, forward; R, reverse.
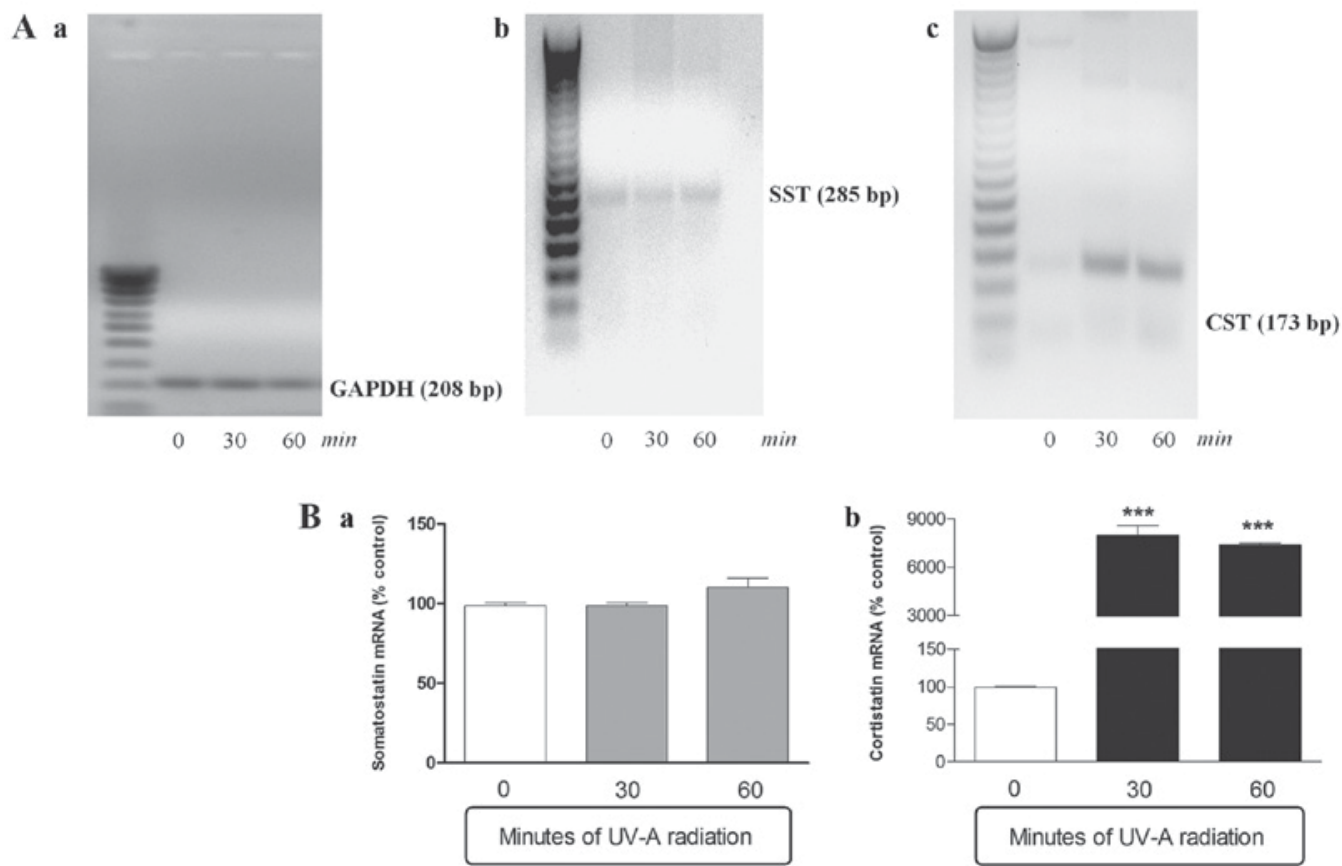

Figure 1. SST and CST expression gene in ARPE-19 cells exposed to ultraviolet UV-A irradiation (30 and 60 min). Panel A: Agarose gels representing mRNA expression levels of (a) glyceraldehide 3-phosphate dehydrogenase (GAPDH), (b) Somatostatin (SST) and (c) Cortistatin (CST). Unmarked lane contains the DNA ladder (50 bp). Panel B: SST (a) and CST (b) densitometric analysis of the gels in panel A. The density of the gel bands were divided by the GAPDH (housekeeping gene) and results were expressed as a percentage of the control band density. Results are from three independent experiments performed in single. ${ }^{* * *} \mathrm{P}<0.01$ vs. control. A representative gel for each experimental condition is shown in the panel A.

SST. The increase of CST mRNA is also associated with an increase of gene expression of SST receptor subtypes, putative CST receptors. Recently, we demonstrated that UV-A radiation for five consecutive hours induced in ARPE-19 cells a rapid increase in ROS levels, which after one hour led to activation of apoptotic events (activation of apoptotic genes, Bax and Caspase-3, and decrease of anti-apoptotic gene, Bcl-2) that in turn contributing to irreversible cell necrosis subsequent (17). 

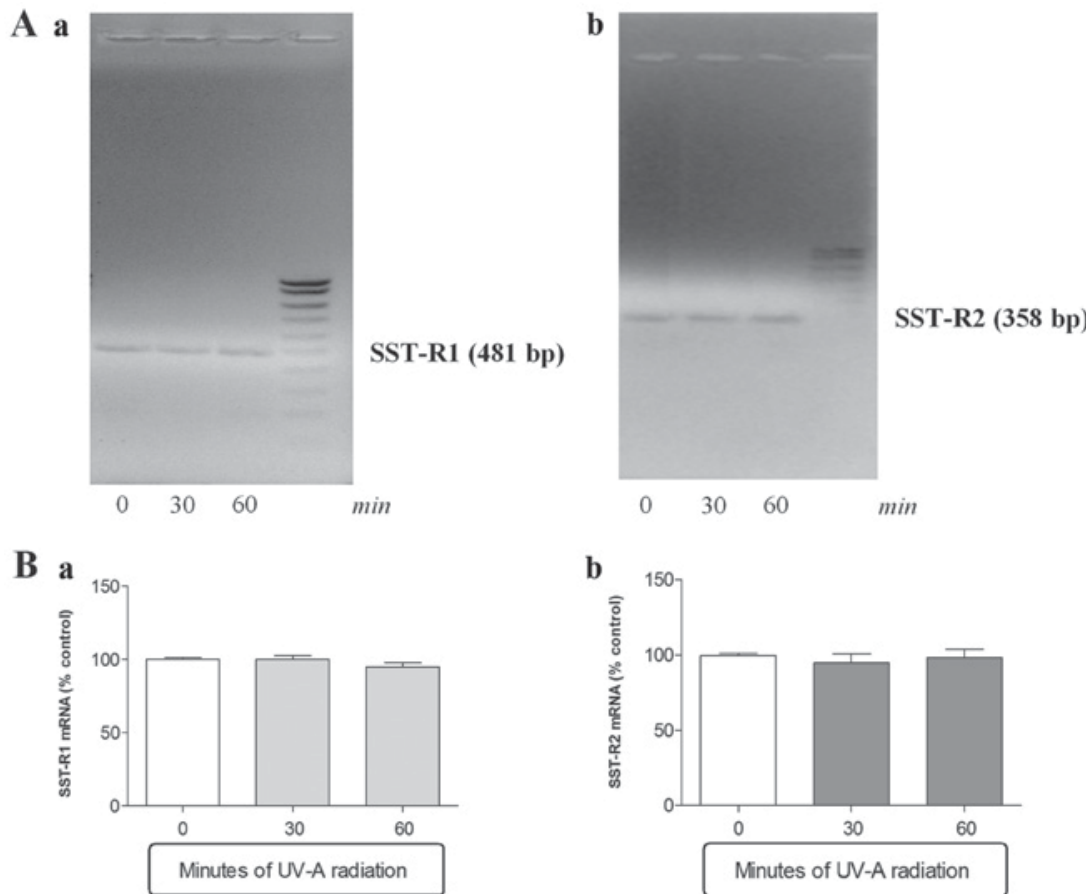

Figure 2. SSTR 1 and SSTR 2 expression gene in ARPE-19 cells exposed to ultraviolet UV-A irradiation (30 and 60 min.). Panel A: Agarose gels representing mRNA expression levels of (a) SSTR 1 and (b) $\mathrm{SSTR}_{2}$. Unmarked lane contains the DNA ladder (100 bp). Panel B: SSTR (a) and SSTR $_{2}$ (b) densitometric analysis of the gels in panel A. The density of the gel bands were divided by the GAPDH (housekeeping gene) and results were expressed as a percentage of the control band density. Results are from three independent experiments performed in single. A representative gel for each experimental condition is shown in the panel A. Data are presented as means \pm SEM.
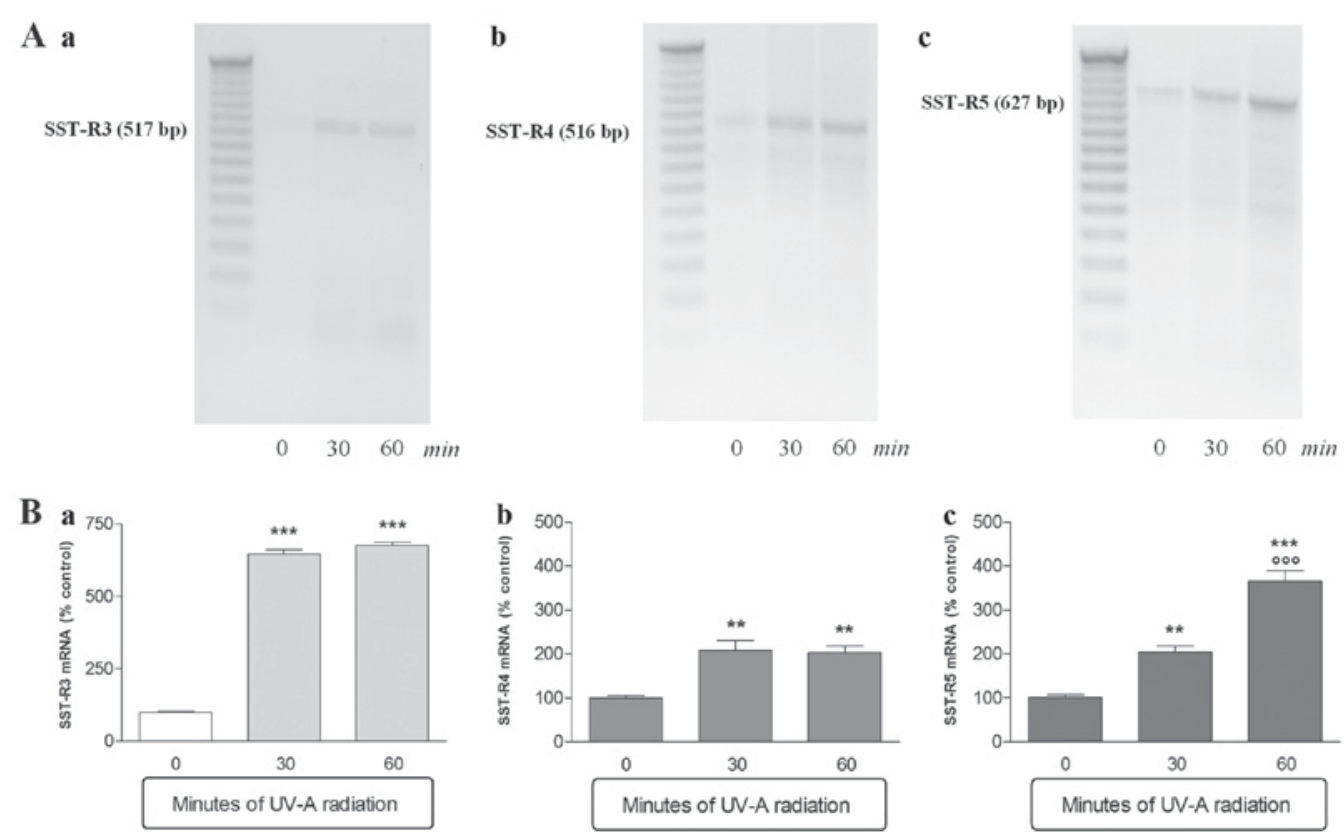

Figure 3. $\mathrm{SSTR}_{3}, \mathrm{SSTR}_{4}$ and $\mathrm{SSTR}_{5}$ expression gene in ARPE-19 cells exposed to ultraviolet UV-A irradiation (30 and 60 min.). Panel A: Agarose gels representing mRNA expression levels of (a) $\mathrm{SSTR}_{3}$ ), (b) $\mathrm{SSTR}_{4}$ and (c) $\mathrm{SSTR}_{5}$. Unmarked lane contains the DNA ladder (50 bp). Panel B: SSTR 3 (a), SSTR (b) $^{2}$ and $\mathrm{SSTR}_{5}$ (c) densitometric analysis of the gels in panel A. The density of the gel bands were divided by the GAPDH (housekeeping gene) and results were expressed as a percentage of the control band density. Results are from three independent experiments performed in single. A representative gel for each experimental condition is shown in the panel A. Data are presented as means $\pm \mathrm{SEM}$. ${ }^{* *} \mathrm{P}<0.01$ and ${ }^{* * *} \mathrm{P}<0.001$ vs. time 0 , respectively. ${ }^{\circ 00} \mathrm{P}<0.001 \mathrm{vs}$. time $30 \mathrm{~min}$.

Therefore, there seems to be a link between increased CST mRNA levels and early apoptotic events triggered by treatment with UV-A, though the pathophysiological role of CST remains unclear. Certainly, CST plays a role only in part that overlaps with that of SST in our experimental paradigm because both peptides are expressed in basal conditions, even if CST mRNA levels are significantly lower compared with those of SST, but only CST is significantly over-expressed 
after exposure to UV-A radiation. On the basis of these findings, one may theorize a protective role for CST in the adaptive response of the RPE exposed to UV-A radiation. Hypothesis is also supported by several literature evidence: i) apoptotic events induced by UV-A radiation coincide temporally with the overexpression of CST observed in our experimental model (17); ii) CST retinal levels are inversely associated with apoptosis and degree of glial activation, two of the characteristics of retinal neurodegeneration (12); iii) CST protects the rat retina against the blockade of oxidative phosphorylation and glycolysis in vitro (14) and iv) CST shows antiangiogenic, neuroprotective, antioxidant, anti-apoptotic and anti-inflammatory properties, in different biological systems $(9,19,20)$. However, further studies will be necessary because we cannot completely exclude that CST overexpression in our study is rather associated with the beginning and support of the apoptosis and necrosis observed in RPE after exposure to UV-A radiation.

CST shares with SST the ability to bind and activate all five cloned SST receptors $\left(\mathrm{SSTR}_{1-5}\right)$, with similar efficacy and potency (3). This analogy might explain the considerable overlapping between CST and SST on several biological actions, including neuroprotective effects in the retina subjected to chemical ischemia or in the diabetic retinopathy $(11,12,14)$. SSTR $_{1-5}$ genes are widely expressed in normal human eye tissues and in particular in retina. hRPE cells express mainly SSTR- $_{-1}$ and SSTR- ${ }_{2}$ in basal condition as shown by RT-PCR and immunohistochemical techniques $(21,22)$, although all five SST receptors have been also detected in D407 h-RPE cells by western blot $(17,23)$. In spite of growing interest about the effects of the SST-receptors activation by SST in the retina, surprisingly little is known on the functions correlated to bond between CST and SST-receptors. Moreover, the role of SST and of its receptors in the RPE is far more complex than that experimental evidences suggest. In fact, an examination of the current scientific literature gives only a sketchy and often conflicting picture of the role of SST and its receptors (22-24). In the present study, the comparison between gene expression levels of SST-receptors and CST or SST shows that: i) SSTR $_{1}$ and $\mathrm{SSTR}_{2}$ gene expression are correlated to high levels of SST mRNA rather than to CST, few expressed, in basal conditions; ii) mRNA levels of $\mathrm{SSTR}_{3}, \mathrm{SSTR}_{4}$ and $\mathrm{SSTR}_{5}$ are little or no detectable in basal conditions and iii) the treatment with UV-A radiations causes a significant increase both in mRNA levels of $\mathrm{SSTR}_{3}, \mathrm{SSTR}_{4}, \mathrm{SSTR}_{5}$ and CST, while it doesn't change the SST and SST- $\mathrm{R}_{1-2}$ basal levels.

At this point in the study, it is important to point out that profiles of the mRNA do not always correlate with the level of protein expression. In fact, the transcript analysis gives us an indication of what genes are active in a specified cell, but nothing about the protein levels actually expressed. However, studying the modulation of the expression of a gene means to investigate in what tissue is expressed, under what conditions it works and what is the effect of its expression. Therefore this study, despite its limitations (evidence only at transcriptional level), allows us to hypothesize that both CST and SSTRs (most probably $\mathrm{SSTR}_{3}, \mathrm{SSTR}_{4}$ and $\mathrm{SSTR}_{5}$ ) are involved in the UV-A-induced adaptive response in the hRPE cells. Certainly, the real physiological role of CST and the involvement of SSTRs in RPE health and disease, require further investigation.
Anyhow these findings provide novel insights on pathophysiological role of CST/SST/SSTRs system and encourage new research avenues for the therapeutic potential of this system in degenerative processes underlying exposure to UV radiation and that are implicated in numerous ocular pathologies, particularly macular degeneration.

\section{Acknowledgements}

The present study was financed by UCSC internal funding (Fondi di Ateneo 2013 to Giuseppe Tringali). Thanks are due to Stefano Cacchione and Sara Luzzi of the Dipartimento di Biologia e Biotecnologie, Sapienza-Università di Roma for providing ARPE-19 cells. We would like also to thank Kathy Lewis for her contribution to experimental work described.

\section{References}

1. de Lecea L, Criado JR, Prospero-Garcia O, Gautvik KM, Schweitzer P, Danielson PE, Dunlop CL, Siggins GR, Henriksen SJ and Sutcliffe JG: A cortical neuropeptide with neuronal depressant and sleep-modulating properties. Nature 381: 242-245, 1996.

2. Spier AD and de Lecea L: Cortistatin: A member of the somatostatin neuropeptide family with distinct physiological functions Brain Res Brain Res Rev 33: 228-241, 2000.

3. Siehler S, Seuwen K and Hoyer D: [125I]Tyr10-cortistatin 14 labels all five somatostatin receptors. Naunyn Schmiedebergs Arch Pharmacol 357: 483-489, 1998.

4. Dello Russo C, Lisi L, Navarra P and Tringali G: Diverging effects of cortistatin and somatostatin on the production and release of prostanoids from rat cortical microglia and astrocytes. J Neuroimmunol 213: 78-83, 2009.

5. Córdoba-Chacón J, Gahete MD, Pozo-Salas AI, Martínez-Fuentes AJ, de Lecea L, Gracia-Navarro F, Kineman RD, Castaño JP and Luque RM: Cortistatin is not a somatostatin analogue but stimulates prolactin release and inhibits GH and ACTH in a gender-dependent fashion: Potential role of ghrelin. Endocrinology 152: 4800-4812, 2011.

6. Córdoba-Chacón J, Gahete MD, Durán-Prado M, Luque RM and Castaño JP: Truncated somatostatin receptors as new players in somatostatin-cortistatin pathophysiology. Ann N Y Acad Sci 1220: 6-15, 2011

7. Markovics A, Szoke É, Sándor K, Börzsei R, Bagoly T, Kemény Á, Elekes K, Pintér E, Szolcsányi J and Helyes Z: Comparison of the anti-inflammatory and anti-nociceptive effects of Cortistatin-14 and Somatostatin-14 in distinct in vitro and in vivo model systems. J Mol Neurosci 46: 40-50, 2012.

8. Tringali G, Greco MC, Lisi L, Pozzoli G and Navarra P: Cortistatin modulates the expression and release of corticotrophin releasing hormone in rat brain. Comparison with somatostatin and octreotide. Peptides 34: 353-359, 2012.

9. Delgado $M$ and Gonzalez-Rey E: Role of cortistatin in the stressed immune system. Front Horm Res 48: 110-120, 2017.

10. Dalm VA, Van Hagen PM, de Krijger RR, Kros JM, Van Koetsveld PM, Van Der Lely AJ, Lamberts SW and Hofland LJ: Distribution pattern of somatostatin and cortistatin mRNA in human central and peripheral tissues. Clin Endocrinol (Oxf) 60: 625-629, 2004

11. Carrasco E, Hernández C, Miralles A, Huguet P, Farrés J and Simó R: Lower somatostatin expression is an early event in diabetic retinopathy and is associated with retinal neurodegeneration. Diabetes Care 30: 2902-2908, 2007.

12. Carrasco E, Hernández C, de Torres I, Farrés J and Simó R: Lowered cortistatin expression is an early event in the human diabetic retina and is associated with apoptosis and glial activation. Mol Vis 14: 1496-1502, 2008.

13. Vasilaki A and Thermos K: Somatostatin analogues as therapeutics in retinal disease. Pharmacol Ther 122: 324-333, 2009.

14. Mastrodimou N, Lambrou GN and Thermos K: Effect of somatostatin analogues on chemically induced ischaemia in the rat retina. Naunyn Schmiedebergs Arch Pharmacol 371: 44-53, 2005. 
15. Roduit $\mathrm{R}$ and Schorderet DF: MAP kinase pathways in UV-induced apoptosis of retinal pigment epithelium ARPE19 cells. Apoptosis 13: 343-353, 2008.

16. Hanus J, Zhang H, Wang Z, Liu Q, Zhou Q and Wang S: Induction of necrotic cell death by oxidative stress in retinal pigment epithelial cells. Cell Death Dis 4: e965, 2013.

17. Tringali G, Sampaolese B and Clementi ME: Expression of early and late cellular damage markers by ARPE-19 cells following prolonged treatment with UV-A radiation. Mol Med Rep 14 3485-3489, 2016.

18. Barltrop JA, Owen TC, Cory AH and Cory JG 5-(3-Carboxylmethoxyphenyl)-2-(4,5-dimethylthiazolyl)-3-(4sulfophenyl) tetrazolium, inner salt (MTS) and related analogs of 3-(4,5-dimethylthiazolyl)-2,5-diphenyltetrazolium bromide (MTT) reducing to purple water-soluble formazans as cell-viability indicators. Bioorg Med Chem Lett 1: 611-614, 1991.

19. Delgado-Maroto V, Benitez R, Forte-Lago I, Morell M, Maganto-Garcia E, Souza-Moreira L, O'Valle F, Duran-Prado M, Lichtman AH, Gonzalez-Rey E and Delgado M: Cortistatin reduces atherosclerosis in hyperlipidemic ApoE-deficient mice and the formation of foam cells. Sci Rep 7: 46444, 2017.
20. Gonzalez-Rey E, Pedreño M, Delgado-Maroto V, Souza-Moreira L and Delgado M: Lulling immunity, pain, and stress to sleep with cortistatin. Ann N Y Acad Sci 1351: 89-98, 2015.

21. Klisovic DD, O'Dorisio MS, Katz SE, Sall JW, Balster D, O'Dorisio TM, Craig E and Lubow M: Somatostatin receptor gene expression in human ocular tissues: RT-PCR and immunohistochemical study. Invest Ophthalmol Vis Sci 42: 2193-2201, 2001.

22. Sall JW, Klisovic DD, O'Dorisio MS and Katz SE: Somatostatin inhibits IGF-1 mediated induction of VEGF in human retinal pigment epithelial cells. Exp Eye Res 79: 465-476, 2004.

23. Papadaki T, Tsilimbaris $\mathbf{M}$, Pallikaris I and Thermos $\mathrm{K}$ : Somatostatin receptor activation (sst(1)-sst(5)) differentially influences human retinal pigment epithelium cell viability. Acta Ophthalmol 88: e228-e233, 2010.

24. Vasilaki A, Papadaki T, Notas G, Kolios G, Mastrodimou N, Hoyer D, Tsilimbaris M, Kouroumalis E, Pallikaris I and Thermos K: Effect of somatostatin on nitric oxide production in human retinal pigment epithelium cell cultures. Invest Ophthalmol Vis Sci 45: 1499-1506, 2004. 